\title{
Los órganos amiboides de Ortega y García Bacca
}

\author{
Ortega's \& García Bacca’s Amoeboid Organs
}

\author{
ALBERTO FERRER GARCÍA*
}

\begin{abstract}
Resumen: El presente artículo pretende exponer la posible influencia que la filosofía de José Ortega y Gasset ejerció sobre el filósofo español del exilio republicano Juan David García Bacca, con el fin de poder determinar hasta qué punto, $y$ de qué modo, fue clave en la gestación del proyecto metafísico garcíabacquiano.

Palabras clave: Juan David García Bacca; Ortega y Gasset; filosofía española; ontología; metafísica.
\end{abstract}

\begin{abstract}
This article aims at analyzing the possible influence that the philosophy of José Ortega y Gasset exerted on the Spanish philosopher of the Republican exile Juan David García Bacca in order to determine the extent to which he was key in the gestation of Bacca's metaphysical project.

Keywords: Juan David García Bacca; Ortega y Gasset; Spanish Philosophy; Ontology; Metaphysics.
\end{abstract}

Rastrear la presencia de Ortega en García Bacca no nos exige sobrevolar en exceso su cartografía literaria1: la figura de este, aunque apocada, se olfatea de inmediato -tarea que alcanzan incluso las narices menos agudas- en su producción más temprana. Ya en su tesis doctoral, Ensayo sobre la estructura lógico-genética de las ciencias físicas $(1935)^{2}$, apunta algunas ideas que atribuye a Ortega y se «detiene» en el análisis de las metáforas como tercera influencia de lo sensible en la física clásica ${ }^{3}$ desde el Góngor $a^{4}$ de Ortega; siendo capaz de destilar -en una quisialquimia que va de lo poético hasta lo científico- toda la teoría atómica de Rutherford de aquellas «luminosas de pólvora saetas».

Recibido: 03/07/2019. Aceptado: 10/07/2019.

* Doctorando en Pensamiento Filosófico Contemporáneo por la Universitat de València; Profesor asociado en el Departamento de Filosofía y Sociología de la Universitat Jaume I y Profesor de Educación Secundaria y Bachillerato en el Colegio San Cristóbal de Castelló·ferrergarcia.alberto@gmail.com I Líneas de investigación: Filosofía española; Estética y Teoría de las artes. Publicaciones recientes: Editor del monográfico Re/incidencias 10: Juan David García Bacca. Quito: Centro Cultural Benjamín Carrión, 2018; «Metáforas y parábolas. Notas para una estética tangencial en J.D. García Bacca», Contrastes: revista internacional de filosofía 24.1 (2019), pp. 143-159.

1 Una cartografía, por cierto, a la que Ricard Balanzá ha dado recientemente forma en el monográfico que el Centro Cultural Benjamín Carrión le ha dedicado. Cf. Ferrer, A. (ed.) (2018), Re/incidencias 10: Juan David García Bacca, Quito: CCBC.

2 [Barcelona]: Tipografia Occitània.

3 Ibid., pp. 32-37.

4 Ortega y Gasset, J. (1966), «Góngora 1627-1927» [en Espíritu de la letra (1927)], en: Obras Completas, tomo III, Madrid: Revista de Occidente, pp. 580-587. 
Coincido con Ignacio Izuzquiza en que la presencia -siempre tenue y momentánea- de Ortega, desde entonces, «le sirve para reafirmar algunas de sus propias tesis y va unida a la valoración que nuestro pensador hace de los momentos verdaderamente originales que se encuentran en la tradición del pensamiento español que le es contemporáneo» ${ }^{5}$; pero poco más.

Yo he tenido dos maestros: Ortega y Machado. Le contaré la primera impresión que tuve al leer a Ortega. Cuando regresé de Alemania, había ido a estudiar Física, Matemática y Escolástica (usted sabe que soy teólogo y que la Teología es una ciencia rigurosa, seca y árida como la Matemática), abrí El espectador y quedé deslumbrado por la belleza de su pensamiento, que me devolvía al contacto con la realidad y la vida ${ }^{6}$

Supongo que a la vejez $-\mathrm{y}$, tras cerca de cuarenta años, pudiendo pisar suelo natal después del Sueño y mentira de Franco- uno siempre tiende a idealizar a quienes, en un momento dado, fueron sus «maestros» o uno los entendió como tales; otra cosa es la huella efectiva que estos pudieron dejar en nosotros. Y, desde luego, en el giro «vital-historicista» que en un momento dado pudiera llegar a sufrir la filosofía garcíabacquiana hay mucho más de Bergson - ¡hasta de Dilthey!? - que de Ortega.

Las ciento quince páginas -en la edición más reciente ${ }^{8}$ - que dedica García Bacca a Ortega en sus Nueve grandes filósofos contemporáneos y sus temas (1947) ${ }^{9}$ no me parecen el acento más pronunciado del orteguismo garcíabacquiano. Si me lo perdonan ustedes -y me lo perdonase García Bacca si pudiera leerme- aquellas páginas las considero un intento de ciencia rigurosa, seca y árida fruto del poso tomista que siempre perduró -y de tanto en tanto reverberaba- en sus líneas:

«Los odres guardan siempre el sabor y aroma del primer vino que en ellos se vertió». En el odre de mi mente, de mi inteligencia, el primer vino filosófico que se vertió fue la filosofía aristotélico-tomista. Y sinceramente, que ese aroma y sabor continuará afectando internamente mi pensamiento [...]. Qué y cuánto de su aroma perdure en mis obras es punto tratado ya aquí. Sabrán -si no continuamente, sí de cuando en cuando- al sabor, al aroma del primer vino. ${ }^{10}$

5 Izuzquiza, I. (1984), El proyecto filosófico de Juan David García Bacca, Barcelona: Anthropos, p. 165.

6 [García Bacca, J.D.] Gurméndez, C. (1977), «La filosofía española surgirá de una reflexión sobre la poesía», El País, n. ${ }^{\circ} 432$, p. 27.

7 Nadie se escandalice por los signos de exclamación: simplemente García Bacca nunca dedicó un capítulo a Dilthey, frente a los sendos dedicados a Bergson y Ortega.

8 (1990), Barcelona: Anthropos. En adelante citaré por esta edición.

9 Vol. II, Caracas: Ministerio de Educación Nacional de Venezuela. El ensayo dedicado a Ortega ya lo había publicado un año antes: (1946), «Ortega y Gasset o el poder vitamínico de la filosofía», Universidad: Órgano de la Universidad de Nuevo León, n. ${ }^{\circ}$ 6, pp. 25 ss. Todos los ensayos incluidos en este volumen formaban parte de un curso dictado, en 1944, en la Universidad de Nuevo León (Monterrey).

10 García Bacca, J.D. (2000), Confesiones: autobiografía íntima y exterior, Barcelona-Caracas: Anthropos-Universidad Central de Venezuela, pp. 15, 50. 
Con aspereza de lengua y un agrio regusto en la boca, creo que el acento recae más bien -o merece la pena hacerlo recaer; y, además, con tilde- en unos pocos ensayos publicados entre Caracas y Montevideo a mediados de los cincuenta, con motivo de la muerte del maestro: «La filosofía de Ortega y Gasset» $(1955)^{11}$, «El estilo filosófico de José Ortega y Gasset» (1956) ${ }^{12}$ y «Pidiendo un Ortega y Gasset desde dentro» (1956) ${ }^{13}$; de qué tanto de orteguismo garcíabacquiano haya en aquellos trataré de ocuparme en las próximas líneas.

No creo que andemos lejos de dar con la mella que realverdaderamente dejó la lectura de Ortega en nuestro filósofo si la pregunta que desde ahora resuene -cual basso ostinato- sea la de: ¿por qué el pensar de Ortega le deslumbró por su belleza devolviéndole el contacto con la realidad y con la vida?

La primera devolución a la realidad es, si se quiere, de cariz telúrico: la falla que abre la posibilidad de poder pensar en lengua materna; algo hasta entonces impensado e impensable. Es con Ortega cuando, al fin y propiamente, podemos hablar de una filosofía en castellano.

¡Ah! Si supiera yo con evidencia en qué consiste el estilo de Ortega y Gasset, la manera orteguiana de acercarse a las cosas, tendríamos lograda la filosofía española; cabría hacer con toda pureza un nuevo ensayo español de filosofar. ¿Un nuevo ensayo, o el primer ensayo de filosofar en español? Yo creo, y no me cansaré de decirlo ante quien sea y contra quien sea, que hasta Ortega no se ha filosofado en español, sino en extranjero. ${ }^{14}$

$\mathrm{Al}$ entender de García Bacca, y también del propio Ortega, quien accede a un estilo accede a la identidad de quien lo produce: entonces, la pregunta -la tarea- por la filosofía española no tiene únicamente un cariz identitario sino que también es, esencialmente, una faena estética. «El auténtico filósofo español no puede ni debe ser solamente ontólogo regional de lo físico, sino esteta, -que el simple y mondo gusto a ser tal vez resulte españolamente desabrido» ${ }^{15}$.

Ya había apuntado Ortega -y es la piedra angular sobre la que edificará García Baccaque todo estaría logrado con ser capaces de acceder al estilo de Cervantes: «porque en estas cimas espirituales reina inquebrantable solidaridad y un estilo poético lleva consigo una filosofía y una moral, una ciencia y una política» ${ }^{16}$. De lo uno se sigue lo otro: de una estética puede derivarse una ontología, una axiología, una ciencia y una política...; «que

11 El Nacional, 24 de noviembre. Citaré por la edición posterior en (1975) Ensayos y estudios, Milano: Vanni Scheiwiller, pp. 65-74.

12 Revista Nacional de Cultura, n. ${ }^{\circ} 114$, pp. 27-36.

13 Entregas de La Licorne, n. ${ }^{\circ}$, pp. 69-77.

14 García Bacca, J.D. (1956), «El estilo filosófico...», p. 27. El subrayado es mío.

15 García Bacca, J.D. (1964), Introducción literaria a la filosofía, Caracas: Universidad Central de Venezuela, p. 275.

16 Ortega y Gasset, J. (1966), «Meditaciones del "Quijote”» [1914], en: Obras Completas, tomo I, p. 363. El subrayado es mío. 
sólo se entiende bien qué nos es algo [...] si paramos mientes en lo que representa para el hombre la poesía y acertamos valerosamente a ver la ciencia sub specie poieseos» ${ }^{17}$.

La metáfora es, dice García Bacca siguiendo a Ortega, la forma más favorable para hacer ciencia. Y lo selló por escrito, pocos años después del Ideas y creencias (1940) de Ortega en «La concepción poética del universo físico» (1944) ${ }^{18}$, al tratar de responder a una cuestión que deberíamos sumar a la que ahora ya nos ocupa: «qqué no será la realidad en su fondo poética, es decir, metafórica?» ${ }^{19}$.

Entonces, ¿por qué el pensar de Ortega le deslumbró por su belleza devolviéndole el contacto con esa realidad, en su fondo poética -metafórica-, y con la vida?

La respuesta no se alejará de la cuestión de la lengua -de una lengua que piensa o quiere pensar- que primeramente esbozábamos: «Ortega es el quehacer español de pensar. Y el primero y la primera vez en la historia en que un español, dentro de su patria, nos hizo sentir el pensar como quehacer, no como pensamiento» ${ }^{20}$. Ortega es pionero y por serlo merecerá, por parte de García Bacca, el eminente título de presocrático de nuestra lengua, que «en los presocráticos el pensar era aún un quehacer. Por eso se ve surgir, manar, brotar en ellos no sólo los pensamientos, sino el pensar mismo» ${ }^{21}$; por eso Ortega lo es, y por ello «a él tenemos que volver, a tal manantial, tanto o más, y con mayor probabilidad de inspiración e inteligibilidad, que a los presocráticos griegos» 22 .

Con todo ello, además, vamos ya haciéndonos a la idea de que el acento del orteguismo garcíabacquiano va a ir por los derroteros de lo inasible, que la tilde de Ortega -como lo será posteriormente la de Machado- es ser un manantial. De digerirlo terminaríamos por ahogarnos, y al propio García Bacca termina por empalagársele aquella manía orteguiana de la metafísica de la razón vital: «Salgámonos antes de que nos arrastre el remolino» ${ }^{23}$. ¿Entonces, qué vida fue la que le deslumbró sino esta del raciovitalismo? ¿o el problema estaba en volver a hacer metafísica de ella? «¿Será la Vida, la Razón vital, el "élan vital" (Bergson), el detonador que desencadene la reacción en serie, y ponga las cosas en ser, el ser en pensar, el pensar en Absoluto?» ${ }^{24}$.

Para Ortega la vida es el hecho radical y el fundamento de su filosofía. Para García Bacca que la vida es ese hecho radical y que a su vez esta es circunstancia son las dos «verdades» fundamentales que le permiten articular ese polémico binomio siemprevivo del élan vital. A ese deslumbre inicial de Ortega le atraviesan un rayo heraclíteo y otro bergsoniano que le suspenden en ese éxtasis amiboide. Trataré de explicarme.

Hay que hacer nuestro quehacer. El perfil de este surge al enfrontar la vocación de cada cual con la circunstancia. Nuestra vocación oprime la circunstancia, como ensayando realizarse en esta. Pero esta responde poniendo condiciones a la vocación.

17 Ibid., (1964) «Ideas y creencias» [1940], tomo V, p. 403.

18 Cuadernos Americanos, n. ${ }^{\circ}$ 3, pp. 69-81.

19 Ibid., p. 70.

20 García Bacca, J.D. (1956), «Pidiendo un Ortega...», p. 71.

21 Ibid., pp. 70-71.

22 García Bacca, J.D. (1955), «La filosofía de Ortega...» [1975], p. 74.

23 García Bacca, J.D. (1956), «El estilo filosófico...», p. 35.

24 Ibid., p. 36. 
Se trata, pues, de un dinamismo y lucha permanentes entre el contorno y nuestro yo necesario. Mi vocación era el pensamiento, el afán de claridad sobre las cosas. Acaso este fervor congénito me hizo ver muy pronto que uno de los rasgos característicos de mi circunstancia española era la deficiencia de eso mismo que yo tenía que ser por íntima necesidad. ${ }^{25}$

Y el pensamiento, para Ortega, o es filosófico o no es; las restantes formas de la intelección no son más que aventuras. Pero en España el pensamiento no era -y dudo a la hora de emplear este pretérito imperfecto...- un quehacer. Y es en este punto donde García Bacca introduce una sutil distinción entre pensar y repetir pensamientos. En España no había derecho a pensar porque el pensamiento no era un quehacer: el «pensamiento»se entregaba hecho. «El español es un tipo de hombre en que el pensar está por hacerse, y por eso pensar es su quehacer; mientras que en otros tipos de hombres tal quehacer está casi cumplido, está casi hecho. Es un hecho» ${ }^{26}$. Para el español, pensar es una tarea; y es una tarea porque «hay, en realidad de verdad, ciertas palabras que sólo se entienden bien en la lengua materna» ${ }^{27}$. Y si pretendemos pensar con un mínimo de seriedad, hacer filosofía de veras, deberíamos saber, con saber de vida -dice García Bacca-, dejando de tratarnos con abstractos, qué es aquello que decimos cuando hablamos; so pena de acabar convertidos en papagayos cartesianos, kantianos o hegelianos.

Un lenguaje de universales son gotas que, desprendidas de la tierra, se tornan niebla de ideas y palabras. En semejante lenguaje no puede haber el necesario timbre del que precisa toda palabra: de armónicos, reales y enrealizantes.

La filosofía comienza a libertarse de su función derivada: de la de altavoz del Altavoz, cuando un hombre se decide, o le nace, filosofar en lengua materna [...]. Con Descartes las lenguas maternas comienzan a ser órganos filosóficos. [...]

El castellano no ha llegado aún a ser órgano vocal del filosofar; y debátese entre una pretendida función de altavoz de Altavoz -de traductor de Originales-, y la exigida por la perfección de una lengua materna que sabe hablar literariamente de todo -menos filosóficamente de filosofía. [...] El castellano es aún altavoz mediato del universo [...]. Nuestra sensiblería española por la independencia se gasta en reclamar un Peñón. ${ }^{28}$

¿De qué tipo de órgano precisa entonces el castellano para tener palabra filosófica? ¿Y quién se lo dará? Ortega es el ojo de España -y «el ojo se abre a idea, mientras y a pesar de estar expuesto a realidad» ${ }^{29}-$, pero no su boca ni la mano que sostiene su pluma. ¿Quién, entonces, la será? En este punto y ocasión, García Bacca, es rotundo: «El equivalente de Kritik der reinen Vernunft o de la Phaenomenologie des Geistes no existe en castellano» ${ }^{30}$.

25 Ortega y Gasset, J. (1964), «Prólogos (1914-1943)», en: Obras Completas, tomo vi, p. 350. El subrayado es mío.

26 García Bacca, J.D. (1956), «Pidiendo un Ortega...», p. 70.

27 García Bacca, J.D. (1970), «Filosofía y lengua» [1966], en: Ensayos, Barcelona: Península, p. 25.

28 Ibid., pp. 27-29.

29 García Bacca, J.D. (1956), «Pidiendo un Ortega...», p. 75.

30 García Bacca, J.D. (1970), «Filosofía y lengua» [1966], p. 29. 
El órgano que Ortega engendra a España -y que no le da boca pero sí unos singulares pies- carece de estructura: el pseudópodo. Un órgano que le permitirá filosofar en forma amiboide: pensar prescindiendo de los símbolos fijos en favor de los dinámicos.

El pseudópodo es [...] un órgano que solo existe en tanto y mientras es útil, que es útil para la traslación, sin las limitaciones y condiciones a que está sometido el pie humano y, más que el pie humano, la bicicleta industrial.

[...] El andar de la amiba es, a un tiempo, creación del órgano adecuado y empleo de él. No queda resto de mecanismo. En cambio, el andar humano es relativamente mecánico. Todo órgano estable en la medida que es estable, con forma fija y funcionamiento predeterminado, tiene el carácter de una máquina, y su uso, de una función mecánica. ${ }^{31}$

«El filosofar de Ortega es a un tiempo creación del órgano adecuado y empleo de él. No queda resto de mecanismo. No hay modo de hacer de su filosofar una filosofía» ${ }^{32}$. Esa será justo la mella más honda que Ortega deje en el organismo garcíabacquiano; siéndole por ende imposible - a aquel que lo pretendiera- hacer de su filosofar una filosofía. Ni Ortega, ni García Bacca, escribirán tratados de nada. Su contextura mental no se los permite: toda sistematización les resulta una carga insoportable para su vida mental, y siempre huyen despavoridos de ella, haciéndonos creer «a veces que nos [han] defraudado o escamoteado a Kant, o Hegel, o Dilthey, o Scheler, o Leibniz; es que íbamos con la secreta intención, e inconfesada exigencia, de que nos [dieran] pie o bicicleta: tratados, sistema» ${ }^{33}$. Íbamos $-\mathrm{y}$ todavía vamos- con la secreta exigencia de que nos dieran cualquiera de las Críticas, o nos entregaran su Fenomenología...

Y García Bacca está convencido de que, cuando la circunstancia le pide -casi le exige, diría yo- a Ortega una exposición detallada sobre Dios sabe qué cariz, aquello hacia donde la amiba de su mente avanza protoplasmáticamente para luego difuminarse y desaparecer, no es mera literatura -y menos aún periodismo- sino honda filosofía. Sin embargo, con perdón de Ortega, aquí la filosofía sí es entonces una aventura. Filosofar en forma amiboide exige colocarse en ese tercer tipo de actividad espiritual al que Ortega daba el nombre de espontaneidad -los impetus originarios de la psique: coraje, curiosidad, amor, odio, agilidad intelectual, gozo, triunfo, confianza en sí y en el mundo, imaginación, memoria... «Funciones espontáneas de la psique, previas a toda cristalización en aparatos y operaciones específicas, [que] son la raíz de la existencia personal» ${ }^{34}$ : de la vida. Los dos tipos de actividades espirituales restantes son la cultura -andar a pie- y la civilización -ir en bicicleta. «Sin ciencia no hay técnica, pero sin curiosidad, agilidad mental, constancia en el esfuerzo, no habrá tampoco ciencia» ${ }^{35}$.

La filosofía de Ortega, como la de García Bacca, carecen -como la amiba- casi por completo de estructura - ni quieren ni pueden tenerla. No tienen órganos especializados tratados sistemáticos-; y sin embargo son filosofía. Una forma muy peculiar de filosofía,

31 Ortega y Gasset, J. (1963), «El espectador III [1921]», en: Obras Completas, tomo II, p. 277.

32 García Bacca, J.D. (1955), «La filosofía de Ortega...» [1975], p. 68.

33 Ibid., p. 68.

34 Ortega y Gasset, J. (1963), «El espectador III [1921]», en: Obras Completas, tomo II, p. 278.

35 Ibid., loc. cit. 
sí; pero filosofía -al menos así lo cree nuestro Juan David. Sus filosofías manan de aquellos ímpetus originarios de su psique; son su filosofar: las raíces de su existencia personal. «Por eso el filosofar de Ortega [y el de García Bacca] da la sensación de manantial, de nacimiento, de frescura, transparencia, suelta gracia, inocencia, simplicidad» ${ }^{36}$. A un germano le nace la filosofía casi en sistema, al francés se le modula en meditaciones, pero al español ha de brollarle cual "“surtidor de novedades", estreno de originalidades, improvisación de espontaneidades» ${ }^{37}$, quedando libre así de todo el mecanicismo que impone la clásica ontología: que, recordémoslo, «el auténtico filósofo español no puede ni debe ser solamente ontólogo regional de lo físico, sino esteta, -que el simple y mondo gusto a ser tal vez resulte españolamente desabrido» ${ }^{38}$. Vivir y filosofar será entonces apertura a creatividad; aunque aquellos ímpetus dejen, necesariamente, «tras sí una estela de productos sedimentados y solidificados en especie» ${ }^{39}$, que «la vida histórica, o la historia viviente, está integrada, o se va integrando, rellenando, de inventos [cultura] -cuyos caracteres son novedad, originalidad, irrupción [espontaneidad]- que, una vez surgidos, estrenados, irrumpidos pasan a "obsoletos" [civilización], usados, desmodados, antiguos o antiguallas, formando, no obstante, estela con sus novedades, originalidades, espontaneidades $»^{40}$.

Ya lo habíamos señalado con anterioridad: filosofar en forma amiboide implica filosofar prescindiendo de los símbolos fijos -carne de obsolescencia- en favor de los dinámicos -de aquellos ímpetus originarios de la psique. Es por ello que Ortega toma distancia del quietismo ontológico clásico -desde Platón, pasando por Kant y llegando hasta Hegel-y defiende un ver activo -en plan y estado de ojo viviente - que le lleva a afirmar: «Vida española, digámoslo lealmente, señores, vida española, hasta ahora, ha sido posible sólo como dinamismo» ${ }^{41}$, pues al no disponer el hombre de una categoría que le revele todas las cosas bajo el aspecto universalísimo de ser, debe él ponerse a esa función dinámica que, más allá de una mera metafísica de la razón vital, ponga en marcha una auténtica técnica ontológica. Ese es el provechoso cariz de la ontología orteguiana que interesa a García Bacca: que «sólo cuando nos ponemos a pensar, comienza la vida filosófica a ser posible como dinamismo. Cuando nos ponemos a pensar, no cuando simple y directamente pensamos, ponemos a las cosas en ser, ponemos el ser de las cosas» ${ }^{42}$. La categoría central ontológica reside entonces en ese poner-verbo de virtud filosófica que, al parecer de García Bacca, no hay Dios que traduzca a lengua extraña. Y el gran logro de Ortega ha sido el de ponernos a pensar a los españoles -que, no lo olvidemos, las «realidades superiores [...] sólo existen para quien tiene la voluntad de ellas» ${ }^{43}$.

El Pensar pone a la cosa en ser. Si ser y cosa fueran, directamente y a la par, lo mismo $[\ldots]$; si $[\ldots]$ pensar y ser fueran exactamente lo mismo, $[\ldots]$ no valdría la pena $[\ldots]$ de intentar una transformación de cosa en ser, o de pensar en ser, o sus contrarias.

36 García Bacca, J.D. (1955), «La filosofía de Ortega...» [1975], p. 69.

37 García Bacca, J.D. (1983), Tres ejercicios literario-filosóficos de economía, Barcelona: Anthropos, p. 101.

38 García Bacca, J.D. (1964), Introducción literaria..., p. 275.

39 García Bacca, J.D. (1983), Tres ejercicios literario-filosóficos de economía, p. 101.

40 García Bacca, J.D. (1983), Tres ejercicios literario-filosóficos de dialéctica, Barcelona: Anthropos, p. 97.

41 Ortega y Gasset, J. (1966), «Vieja y nueva política» [1914], en: Obras Completas, tomo I, p. 280.

42 García Bacca, J.D. (1956), «El estilo filosófico...», p. 34.

43 Ortega y Gasset, J. (1966), «Meditaciones del “Quijote”» [1914], p. 336. 
Pero si cosa y ser difirieran en un altísimo coeficiente, si entre pensar y ser valiera una ecuación de transformación parecida a la einsteiniana en que al pasar de ser a pensar ganáramos inmensamente en tipo de realidad, valdría la pena de estudiar la técnica ontológica que hiciera efectivos tales cambios, transustanciaciones más bien..$^{44}$

Ahora estaríamos en disposición de entender por qué al denso ensayo sobre Ortega en sus Nueve grandes filósofos... le precede el dedicado a William James y su voluntad de introducir esa verdad a la que él llama «real»: «la verdad como invento para descubrir, dominar, transformar lo real» ${ }^{45}$. No es lugar ni momento para ocuparnos del singular trinomio -W. James-Ortega y Gasset-A.N Whitehead ${ }^{46}$ - que García Bacca traza en aquel segundo volumen, pero sí para plantearnos de nuevo la cuestión de si «será la Vida, la Razón vital, el "élan vital" (Bergson), el detonador que desencadene la reacción en serie, y ponga las cosas en ser, el ser en pensar, el pensar en Absoluto» ${ }^{47}$.

La amiba, decíamos, improvisa sus órganos a medida de sus circunstanciales necesidades y García Bacca entiende que «el amiboide filosofar de Ortega es un caso modélico en la historia de la filosofía - no veo otro caso desde Sócrates-, en que la función de filosofar se ha mantenido en su fase de creación, de surgimiento, de invención, de jaillisement de nouveauté» ${ }^{48}$, y no se ha cristalizado en ningún aparato o imperativo cultural, ni ha decaído en instrumento obsoleto de una civilización. No le sucedió así a Bergson, que, al entender de García Bacca, «estuvo a punto, y de cuando en cuando daba en el punto, de filosofar a lo amiboide ${ }^{49}$, de filosofar a lo manantial, hacerlo en estilo equivalente al de Ortega -aunque en el suyo y en su lengua.

Mas el filosofar de Bergson no se mantiene, de ordinario, sí en momentos raros, en el estado de creación de novedad, de amiba. Su estado normal es el de pie: de órgano cultural perfectamente estructurado; y sus obras están, por este motivo, muy cerca del sistema; viviente, sin duda, pero con los inconvenientes, y ventajas, que Ortega anota en la cuenta de toda vitalidad diferenciada: especificaciones de la vitalidad psíquica dentro de cauces normativos e infranqueables. ${ }^{50}$

Cabría preguntarse si no estará pecando García Bacca de excesiva veneración hacia el maestro que tiene todavía prácticamente de cuerpo presente -recordemos que estas líneas las publica a un mes escaso del tránsito de Ortega-, y aquello de filosofar en amiboide es sólo tarea que uno puede emprender a ratos sueltos -y que emprenden hombre sueltos, como el

44 García Bacca, J.D. (1956), «El estilo filosófico...», p. 36.

45 García Bacca, J.D. (1990), Nueve grandes filósofos..., p. 259.

46 En otros lugares, y por separado, me ocupado con cierto detenimiento de los ensayos dedicados a William James y A.N. Whitehead. Cfr. Ferrer, A. (2016), «El realismo de la verdad: García Bacca lee a William James», Agora: papeles de filosofía, n. 2, pp. 65-83 y Ferrer, A. (2017), «Una metafísica del ser en cuanto creación: Juan David García Bacca lee a Alfred North Whitehead», Ideas y valores, n. ${ }^{\circ}$ 164, pp. 203-227.

47 García Bacca, J.D. (1956), «El estilo filosófico...», p. 36.

48 García Bacca, J.D. (1955), «La filosofía de Ortega...» [1975], p. 69.

49 Ibid., loc. cit.

50 Ibid., p. 70. 
maestro Ortega, Bergson o él mismo-, «en actos discontinuos, en oficios diversos, so pena de que [-y la advertencia es del propio García Bacca-], si se lo [hiciera] en un acto continuo, en un rato permanente, en un oficio irrenunciable, [quedaría] pasmado, suspenso» ${ }^{51}$. «Las improvisaciones [-continúa García Bacca en otro lugar-] son, por constitución, breves, a ratos sueltos, en casos especiales. No se puede estar largo rato asustado, insultando, sospechando... Se decae -por el influjo de las leyes físicas- [...] en hábitos, costumbres, rutina, hastío, tibieza ${ }^{52}$... Del mismo modo decaería ese filosofar en amiboide si quedara suspenso y no aconteciese a chispazos o centelleos, a ocurrencias, por modo de gana o de desgana, sin quedar preso por ninguno de aquellos ratos sueltos. «No es luz continua; durable horas, días. Y menos aún, durable a voluntad $»^{53}$.

Entonces, no creo que haya distinción real entre el estilo de filosofar a lo fuente, venero o manantial, de Ortega y el de Bergson. Tampoco con el de García Bacca. Los tres coinciden en filosofar, a ratos sueltos, con los ímpetus originarios de la psique. Uno no puede vivir, ni vivirse, dándose órganos a diario; necesita andar por su propio pie $\mathrm{y}$, de tanto en tanto, cuando estos ya no dan más de sí, echar mano de la bicicleta o incluso del automóvil -y hasta del taxista. Los órganos también precisan de aquellas vacaciones morales que James nos sugería tomarnos; aunque «el filosofar amiboide [lleve] fabulosas ventajas sobre el pie y la bicicleta, sobre el filosofar sistemático» ${ }^{54}$.

El paradigma que se encarna en Ortega y se repite tanto en Bergson como en García Bacca -y también en Santayana- es el de aquel que sufre esas tres transformaciones que nos remiten, irremediablemente, a las ya clásicas con las que Nietzsche abre su Así habló Zaratustra:

Su fase de bicicleta, actividad espiritual a servicio de mecanismos y técnicas filosóficas cede el lugar inmediatamente a la de pie: a las funciones culturales del pensar científico, de la moralidad, de la creación artística; y desde [ellas] anda por su propio pie, y a servicio de su propia vida, en dirección siempre, desde los imperativos culturales -Verdad, Bondad, Belleza-, hacia los vitales, hacia los amiboides: Sinceridad, Impetuosidad, Deleite..$^{55}$

Tampoco uno puede pasar la vida entera en aquella rueda, movida por sí misma, del santo decir sí: en el inocente olvido de la infancia; ni rugiendo el «yo quiero» de la bestia; ni arrodillado como el camello que quiere que se le cargue bien.

Como el Zaratustra nietzscheano Ortega va a predicar a los españoles, como señor en su propio desierto, que se debe «templar la Verdad con sinceridad, atemperar Bondad con

51 García Bacca, J.D. (2003), Tres ejercicios literario-filosóficos sobre verdad, Caracas: Los libros de El Nacional, p. 135.

52 García Bacca, J.D. (2001), Divertimientos y migajas, Quito: Casa de la Cultura Ecuatoriana Benjamín Carrión, p. 19.

53 García Bacca, J.D. (1984), Infinito, transfinito, finito, Barcelona: Anthropos, p. 80.

54 García Bacca, J.D. (1955), «La filosofía de Ortega...» [1975], p. 74.

55 Ibid., p. 70. 
impetuosidad; poner a tono Belleza con deleite» ${ }^{56}$; completar los imperativos objetivos con los subjetivos.

Ortega atemperó, en su persona y obras, con incitante ejemplaridad [...] los imperativos culturales con los vitales. Verdad con sinceridad. No afirmar nada, por sublime, hierático, patente que sea, si no se lo puede sostener con sinceridad. La Verdad no tiene derecho alguno por serlo, a no ser que pueda arrebatar, por las buenas, nuestro sincero sentimiento.

[...] El Bien tiene que ser, y es su primer deber, aperitivo para la vida. Bien que no sea capaz de hacerse valer ante la vida y para la vida, no es bueno. [...] Ética vital, sentida y sentible.

Ejemplarmente también para nosotros templó el imperativo cultural puro y absoluto de Belleza con el vital de Deleite. Bello-y-bueno-de-ver, la kalo-kai-agathia, constituyó la fusión normativa, de belleza y bondad, característica de la época auroral, heroica y típica del heleno. Bello-y-bueno-de-vivir, todo a la una y en uno, fue el ideal de Ortega, en Moral, en Estética. Y por el atemperamiento de Belleza con deleite resultan tan deliciosas las obras de Ortega, deliciosas de leer, deliciosas de pensar, deleitables al gusto literario que sepa paladear y regodearse en las palabras, y no se las trague de un golpe. ${ }^{57}$

La exigencia primera -y primaria- es, sencillamente, la Vida: una belleza en la que gocemos deleitarnos, una moral incitadora, una verdad vitalmente sincera. En definitiva, una verdad, bondad y belleza que no obligan. Nada se saca del célebre trinomio de imperativos por la fuerza. Se acatan en la medida en que despiertan nuestros ímpetus, entusiasmos, apetencias. No es cuestión ya de verdad o falsedad, sino de gana o desgana. Ni la Verdad, ni la Bondad, ni la Belleza pueden vivirse como norma o mandato.

No basta [...] que una idea científica o política parezca por razones geométricas verdadera para que debamos sustentarla. Es preciso que, además, suscite en nosotros una fe plenaria y sin reserva alguna. Cuando esto no ocurre, nuestro deber es distanciarnos de aquella y modificarla cuanto sea necesario para que ajuste rigorosamente con nuestra orgánica exigencia. ${ }^{58}$

Verdad, Bondad, Belleza, viven por gracia de mi Libertad. Nuestro deber, dice Ortega y recalcará García Bacca, es la distancia con aquello que nos resulta invivible y, actuando en consecuencia, modularlo por virtud de nuestra voluntad hasta que acople con nuestra orgánica exigencia. «La Verdad será tan verdadera cuanto quiera; mas no tiene razón, si no se la damos. La verdad cobra razón por gracia nuestra, por don nuestro. [...] El hombre es racional, por naturaleza; pero da razones y la razón a la verdad, por gracia; y a ratos y a veces por gana, o la niega por desgana» ${ }^{59}$. No basta con que uno tenga razón, hace falta

56 Ibid., pp. 70-71.

57 Ibid., pp. 72-73.

58 Ortega y Gasset, J. (1966), «El tema de nuestro tiempo [1923]», en: Obras Completas, tomo III, p. 171.

59 García Bacca, J.D. (1956), «Pidiendo un Ortega...», pp. 72, 74. 
que se la den. Y aquí William James jugará un papel determinante; pero es ahora Ortega quien nos ocupa.

Si Ortega es, decíamos líneas más arriba, el ojo de España es porque, a un país que sólo sabía ver, le dio la facultad de mirar. Frente a una contemplación pasiva de ese caos que son las ideas, frente a un detener la vista en ese orden ideal en el que todo está hecho desde siempre y para siempre, Ortega nos enseñó a mirar activamente, a sernos ojos vivientes, a sentirnos conocedores, en activo y eficaz sentido de la palabra. Esa fue la verdadera vocación de Ortega: enseñarnos a mirar. Y de ahí brolló esa ontología que se nos brinda como plan de trabajo para una metafísica de la razón vital, de la que, ya lo vimos, García Bacca huía. Me pregunto, llegados a este punto, si tal metafísica resulta compatible con ese órgano amiboide del filosofar. García Bacca no lo debió sentir así y por ello prefirió, llegado el momento, echar el freno donde lo creyó oportuno. Él tampoco andaba libre de obsesiones, y la suya era la de una metafísica de la creación y de la novedad. Cuando afirma: «Sólo Ortega filosofa siempre, y escribe continuamente en filosofante estilo amiboide: en fase de surtidor bien surtido de novedades, en evolución creadora» ${ }^{60}$; se pone al descubierto. Sus íntimos anhelos se vuelcan en la idílica figura del maestro. De Ortega quiso aprender esa ontología que es, en realidad de verdad, creación de la mente humana; de sus ímpetus. Quiso aprender a mirar, que «si no hubiera más que un ver pasivo quedaría el mundo reducido a un caos de puntos luminosos. Pero hay sobre el pasivo ver un ver activo, que interpreta viendo y ve interpretando; un ver que es mirar» ${ }^{61}$.

Acabo con una impertinencia plástica: a finales de los setenta, justo el año en que García Bacca pisa de nuevo España tras su exilio forzoso en 1938 -1977-, Manuel Hernández Mompó inaugura, en la Galería Juana Mordó de Madrid, Alarós; circunstancias de metacrilato que «ponen los colores y las formas en el aire, aire de la vida en libertad» ${ }^{62}$. Permítanme imaginar por un momento -a modo de cierre visual para estas líneas; confiando sea en realidad una apertura- que García Bacca detuvo sus pasos ante el escaparate de la célebre galería madrileña, y allí, con los ojos clavados en un alaró, sintió deslizarse el hálito del maestro. Mompó había dado aquel nombre a esas urnas amiboides de metacrilato por el pueblo mallorquín en el que por entonces, rodeado de olivos milenarios, habitaba: Alaró. «Son objetos para ver todos sus lados y para ser colocados en espacios abiertos, para acompañar a la naturaleza» ${ }^{63}$.

Ortega nos enseñó que sólo unas pocas cosas de este mundo, además de estar patentes a todas, están abiertas a todas; y que estar abierto «implica recibir una realidad, desconectando y neutralizando su causalidad; admitirla de visita, no de invasora ${ }^{64}$. No otra, a mi entender, es la función de aquellos alarós. No otra es la función del filosofar, ya no en

60 García Bacca, J.D. (1955), «La filosofía de Ortega...» [1975], p. 72.

61 Ortega y Gasset, J. (1966), «Meditaciones del “Quijote”» [1914], p. 336.

62 Aranguren, J.L. (1991), «Prólogo», en: J.F. Yvars (coord.): Manuel H. Mompó, Valencia: Vicent García Editores, p. 9.

63 H. Mompó, Manuel (1991), «Un poco de mi vida», en: J.F. Yvars (coord.): Manuel H. Mompó, p. 38.

64 García Bacca, J.D. (1956), «Pidiendo un Ortega...», p. 74. 
amiboide, sino en mediterráneo: ser «meros soportes de los órganos de los sentidos» ${ }^{65}$. Es la exigencia de nuestro mar interno. Encontrar, como lo hiciera Mompó, «un soporte que [anule] el blanco pintado de la superficie, viéndose sólo los colores y formas en el aire, quedando liberados del espacio limitado» ${ }^{66}$.

\section{Bibliografía}

Aranguren, J.L. (1991). «Prólogo». En: J.F. Yvars (coord.), Manuel H. Mompó. Valencia: Vicent García Editores, pp. 9-10.

García Bacca, J.D. (1944). «La concepción poética del universo físico», Cuadernos Americanos, n. ${ }^{\circ}$ 3, pp. 69-81.

García Bacca, J.D. (1956). «El estilo filosófico de José Ortega y Gasset», Revista Nacional de Cultura, n. ${ }^{\circ} 114$, pp. 27-36.

García Bacca, J.D. (1956). «Pidiendo un Ortega y Gasset desde dentro», Entregas de La Licorne, n. ${ }^{\circ} 8$, pp. 69-77.

García Bacca, J.D. (1964). Introducción literaria a la filosofía. Caracas: Universidad Central de Venezuela.

García Bacca, J.D. (1970). «Filosofía y lengua». En: Ensayos. Barcelona: Península, pp. 25-29.

García Bacca, J.D. (1975). «La filosofía de Ortega y Gasset». En: Ensayos y estudios. Milano: Vanni Scheiwiller, pp. 65-74.

García Bacca, J.D. (1983). Tres ejercicios literario-filosóficos de dialéctica. Barcelona: Anthropos.

García Bacca, J.D. (1983). Tres ejercicios literario-filosóficos de economía. Barcelona: Anthropos.

García Bacca, J.D. (1984). Infinito, transfinito, finito. Barcelona: Anthropos.

García Bacca, J.D. (1990). Nueve grandes filósofos contemporáneos y sus temas. Barcelona: Anthropos.

García Bacca, J.D. (2000). Confesiones: autobiografía íntima y exterior. Barcelona-Caracas: Anthropos-Universidad Central de Venezuela.

García Bacca, J.D. (2001). Divertimientos y migajas. Quito: Casa de la Cultura Ecuatoriana Benjamín Carrión.

García Bacca, J.D. (2003). Tres ejercicios literario-filosóficos sobre verdad. Caracas: Los libros de El Nacional.

Gurméndez, Carlos (1977). «La filosofía española surgirá de una reflexión sobre la poesía», El País, n. ${ }^{\circ}$ 432, p. 27.

Hernández Mompó, Manuel (1991). «Un poco de mi vida». En: J.F. Yvars (coord.), Manuel H. Mompó. Valencia: Vicent García Editores, pp. 31-39.

Izuzquiza, Ignacio (1984). El proyecto filosófico de Juan David García Bacca. Barcelona: Anthropos.

65 Ortega y Gasset, J. (1966), «Meditaciones del “Quijote”» [1914], pp. 348-349. El subrayado es mío.

66 H. Mompó, Manuel (1991), «Un poco de mi vida», p. 38. 
Ortega y Gasset, J. (1963). «El espectador III». En: Obras Completas. Tomo II. Madrid: Revista de Occidente, pp. 225-313.

Ortega y Gasset, J. (1964). «Ideas y creencias». En: Obras Completas. Tomo v. Madrid: Revista de Occidente, pp. 377-489.

Ortega y Gasset, J. (1964). «Prólogos (1914-1943)». En: Obras Completas. Tomo VI. Madrid: Revista de Occidente, pp. 245-512.

Ortega y Gasset, J. (1966). «El tema de nuestro tiempo». En: Obras Completas. Tomo III. Madrid: Revista de Occidente, pp. 141-242.

Ortega y Gasset, J. (1966). «Meditaciones del "Quijote"». En: Obras Completas. Tomo I. Madrid: Revista de Occidente, pp. 309-400.

Ortega y Gasset, J. (1966). «Vieja y nueva política». En: Obras Completas. Tomo I. Madrid: Revista de Occidente, pp. 265-307. 
